\title{
New intelligent network approach for monitoring physiological parameters: the case of Benin
}

\author{
Daton Medenou ${ }^{1} \cdot$ Mêtowanou H. Ahouandjinou $^{1} \cdot$ Davide Piaggio $^{2} \cdot$ Roland C. Houessouvo $^{1} \cdot$ Leandro Pecchia $^{2}$. \\ Thierry R. Jossou ${ }^{1}$
}

Received: 18 December 2019 / Accepted: 9 March 2020

(C) The Author(s) 2020

\begin{abstract}
Benin health system is facing many challenges as: (i) affordable high-quality health care to a growing population providing need, (ii) patients' hospitalization time reduction, (iii) and presence time of the nursing staff optimization. Such challenges can be solved by remote monitoring of patients. To achieve this, five steps were followed. 1) Identification of the Wireless Body Area Network (WBAN) systems' characteristics and the patient physiological parameters' monitoring. 2) The national Integrated Patient Monitoring Network (RIMP) architecture modeling in a cloud of Technocenters. 3) Cross-analysis between the characteristics and the functional requirements identified. 4) Each Technocenter's functionality simulation through: a) the design approach choice inspired by the life cycle of V systems; b) functional modeling through SysML Language; c) the communication technology and different architectures of sensor networks choice studying. 5) An estimate of the material resources of the national RIMP according to physiological parameters. A National Integrated Network for Patient Monitoring (RNIMP) remotely, ambulatory or not, was designed for Beninese health system. The implementation of the RNIMP will contribute to improve patients' care in Benin. The proposed network is supported by a repository that can be used for its implementation, monitoring and evaluation. It is a table of 36 characteristic elements each of which must satisfy 5 requirements relating to: medical application, design factors, safety, performance indicators and materiovigilance.
\end{abstract}

Keywords Architecture - Requirements · Hospital · Patient · Repository · RNIMP - Simulation · SysML · System · Technocenter $\cdot$ WBAN

Mêtowanou H. Ahouandjinou

heribert.metowanou@gmail.com

Daton Medenou

daton.medenou@epac.uac.bj

Davide Piaggio

D.Piaggio@warwick.ac.uk

Roland C. Houessouvo

rolandchouessouvo@gmail.com

Leandro Pecchia

L.Pecchia@warwick.ac.uk

Thierry R. Jossou

thierry.djossou@gmail.com

1 Electrotechnical Laboratory of Telecommunications and Applied Informatic (Polytechnic School of Abomey-Calavi), Unviversity of Abomey-Calavi, Cotonou, Benin

2 School of Engineering, University of Warwick, Warwick, UK

\section{Introduction}

The health system in Benin faces several challenges including: (i) the need to provide affordable high-quality health care to a rapidly growing population, (ii) the reduction of hospitalization time for patients, (iii) and the optimization of the nursing staff presence time [1]. In order to deliver good health care services to all the Beninese population, including the rural one, any health policy in Benin must consider the 5295 villages and city districts, which are organized in 546 boroughs, 77 communes, 34 health zones, and 12 departments. The new communication tools and the latest technologies of the Information and communications technology (ICT) world are appropriate to face such challenges. Among such technologies, our main interest lies in sensors. Indeed, thanks to the Advanced Embedded Systems and Wireless Technologies (SETSF), the Sensors Wireless Networks (WSN) are frequently used in medical applications in recent decades. Hence, the emergence of 
Medical Wireless Sensor Networks (MWSN) used in Wireless Body Area Network systems to improve the quality of care and record the medical monitoring of patients.

The MWSN are characterized by their sensor nodes mobility, easy deployment and self-organization. Therefore, the MWSN are very convenient for monitoring the elderly, the disabled, people at risk or with chronic diseases and to monitor their living environment [2]. As of today, the MWSN are used to monitor vital parameters such as temperature, blood pressure or heart rate [3] [4] [5]. The MWSN in the WBANs improve patient's quality of life, real-time follow-up and emergency decision-making [6] [7].

Different approaches to the implementation of MWSN can be found in the literature. Charlton et al. [8] invented a dynamically operating architecture for a health surveillance system. This architecture takes into account the design of hardware individually and the assembly of several distinct modules for the health surveillance function. Ali et al. [9] worked on a hybrid web application scheme in wireless sensor networks for health care surveillance. The authors proposed a cost-effective architecture for a remote healthcare monitoring system using a pulse and temperature sensor. The authors in [10] worked on the integration of wearable sensors for ubiquitous health monitoring, showing the limitations of traditional e-health. The latter goes beyond the clinical setting and requires more technological tools than wearable sensors in body sensor networks.

Furthermore, in [11] the logic level including functionalities for the real-time monitoring of cardiac patients using sensors and smartphones was made accessible via a physician-patient interface system, acting as presentation tier. An evaluation of the system proposed by the authors shows its reliability and usefulness with data security. Similarly in [12] [13] wireless sensor networks have been used for ECG health care monitoring. Several ECG monitoring systems have been reviewed and their main concepts presented. The system proposed in [13] allows monitoring the heart rate and rhythm, the temperature, and the oxygen level in cardiac patients, reducing the stress level and pressure of physicians and patients.

$\mathrm{Xu}$ et al. have designed in [14] an m-Health monitoring system based on a cloud computing platform consisting of three modules that cooperate to implement basic health monitoring functions. Besides, the authors in [15] worked on intelligent healthcare systems with wireless sensor networks by presenting a three-level energy-efficient model for healthcare. In this architecture, they use the Zigbee communication standard with an Arduino card. The proposed model was implemented with one patient and two sensors.

Several other authors have worked on health surveillance systems based on wireless sensor networks for the improvement and continuous monitoring of healthcare. Like Dragos et al. [16], who conducted a comparative study of wireless sensor nodes for health surveillance with an emphasis on embedded computing capabilities and the ability of nodes. Tunas et al. [17] worked on a wireless sensor for the health surveillance of the elderly and the disabled. The system proposed by the authors consists of low-cost components and reduces the cost of services for health care providers. Nabi et al. [18] discuss the use of IoT sensors for health monitoring of patients. The authors proposed a health monitoring architecture based on IoT sensors, informing patients of the possible precautionary measures to be taken.

Data security issues in health surveillance systems based on wireless sensor networks were also addressed in the research. For example, Sathya et al. worked in [19] on the security of remote health monitoring systems using portable wireless sensor networks. Their work showed the need for the security of health data to avoid deadly risks to patients. The different existing systems and algorithms are being reviewed to identify the best performance comparing encryption and decryption time.

An approach to secure the exchanges between the sensor nodes of a WBAN was proposed by Poon [20]. Specifically, the addressed problem is related to the confidentiality and integrity of data, the question being: how do the nodes of a WBAN know that they belong to the same patient? To answer this question, the authors proposed a solution based on a «biometrics» approach, which is an identification technique based on the physiological or behavioral characteristics of the individual. This approach makes it possible to identify the sensor nodes and to secure the distribution of the encrypted key, based on symmetric cryptography. The choice of this biometry is based on the heartbeat information called «interpulse interval (IPI)». This is an example of a solution that achieves a high level of security with less calculation and memory.

Other approaches are available in the literature, presenting an actimetric monitoring telemonitoring system [21], the detection of attacks in a WBAN remote medical surveillance system [4], the impact of connected objects in a health care system and their importance in the prevention of diseases in health applications [22]. However, it is important to highlight the fact that the success of these health surveillance systems depend not only on data collection and processing, but also on the understanding of the environment of a subject so that contextual care can be delivered [23].

Concluding, we note that the challenges of any medical surveillance system lie in the proper design of the network architecture. In light of this, our work aims at modeling an Integrated Patient Monitoring Network (RIMP) in the Beninese health system, through the use of wireless medical sensor networks in WBAN systems. This paper presents the methodology adopted for the work, the results obtained, the analysis of the results, the discussion, and the envisaged perspectives. 
Fig. 1 WBAN monitoring system

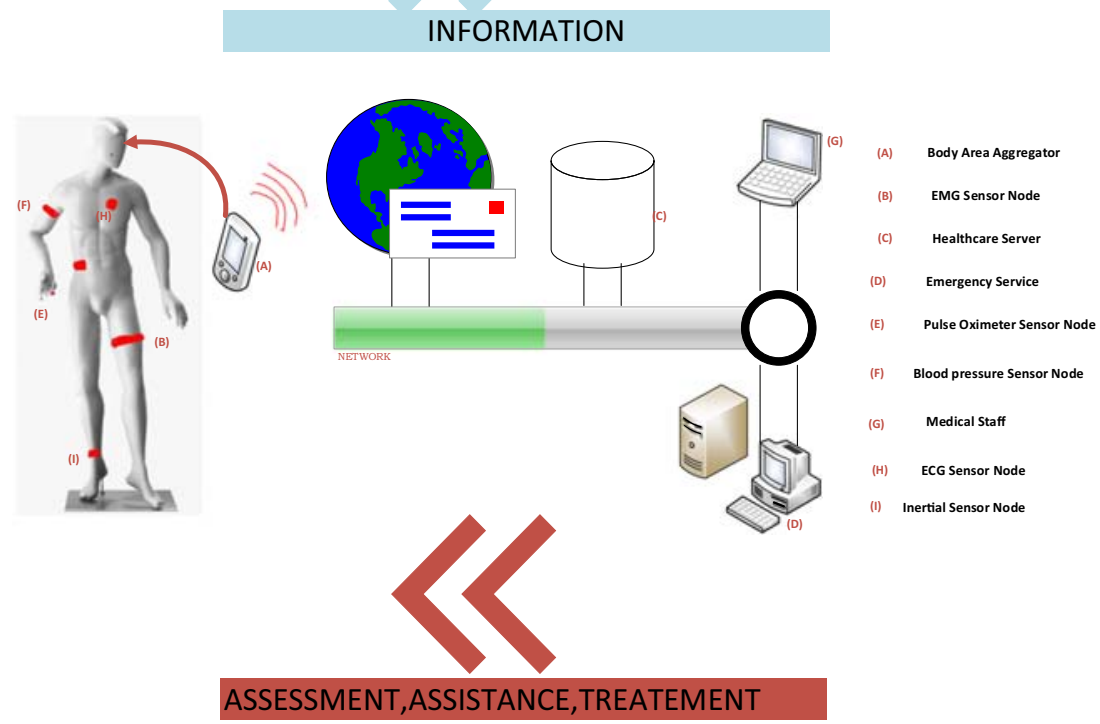

\section{Material and method}

\subsection{Material}

In addition to resources from the literature, we used: MS Visio for the network architecture, SysML for modeling, a Dell computer with $8 \mathrm{~GB}$ of RAM and 2 TB of disk, and data on the health pyramid of Benin. Moreover, we based our work on the model of the WBAN remote medical surveillance system, shown in Fig. 1, and on the model of a WBAN comprehensive medical surveillance system, which is divided into five subsystems [24], as shown in Fig. 2.

Several medical sensors are deployed on the patient's body to measure several physiological parameters. These nodes are sensors capable of harvesting and autonomously transmitting environmental data. The position of these nodes is not necessarily predetermined.

\section{Method}

A five-step methodology was adopted:

1) The different characteristics of the WBAN systems and the physiological parameters that can be monitored on a patient were identified;

2) The national architecture of the RIMP, in the form of a cloud of Technocentres at 6 levels (i.e., National,
Fig. 2 Architecture of a medical surveillance system

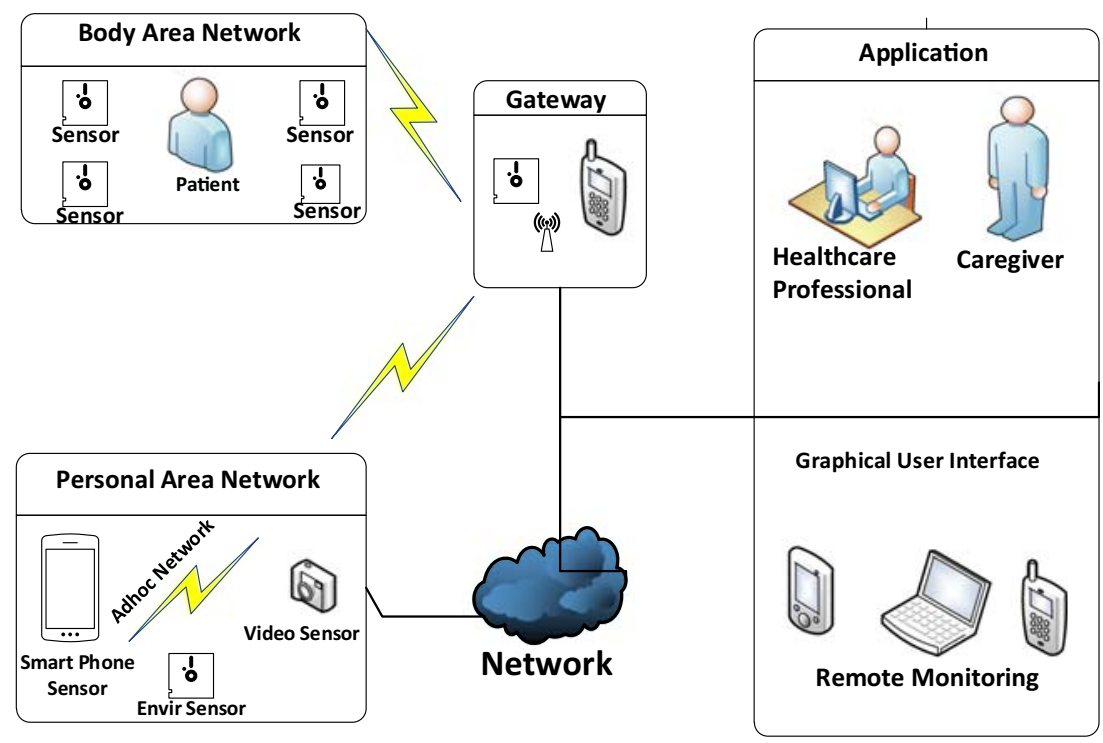


Departmental, Health Zone, Communal, Borough, Village and City District), was modeled;

3) Cross-analysis was performed among the characteristics and the identified functional requirements;

4) The functionality of each Technocentre was simulated through:

a) the choice of a design approach inspired by the life cycle of V systems;

b) functional modeling through Language SysML;

c) the comparative study of the choice of communication technology and different architectures of sensor networks;

5) The material resources of the national RIMP were estimated according to physiological parameters.

\section{Results}

A. The identification of the different characteristics of WBAN systems

A total of 36 characteristics of WBAN systems were listed in Table 1.

B. Cross-analysis between characteristics and functional requirements identified

Table 2 shows the binary matrix of a well-designed WBAN and comprises of the binary matrix of the requirements $\left(I_{i}\right)$ with $i$ from 1 to 5 and the characteristics of the requirements $\left(I_{i_{j}}\right)$ with $j$ from 1 to 36 . To do this, we have added to the previous requirements the one related to the Materiovigilance in order to guarantee the maintenance and minimize the potential risks of the network.
C. Modeling the function of a smart hospital

Notation and formulation.

Table 1 and 2 show the characteristics of a WBAN network for healthcare monitoring. These character-defining elements constitute a benchmark for assessing any WBAN architecture for healthcare monitoring. A good healthcare monitoring architecture is then based on a good design of the WBAN network. Let us define the following:

$\boldsymbol{f}_{\boldsymbol{c}}(\boldsymbol{W B} \boldsymbol{A} \boldsymbol{N})$ : conception function.

$\boldsymbol{E}(\boldsymbol{j})$ : element $j$ of the medical application requirements. With $j$ from 1 to 36 ;

$f_{E}:$ function of the requirements of the medical application;

$\boldsymbol{f}_{\boldsymbol{E}}=\sum_{j=1}^{n=36} E(j)$

$\boldsymbol{f a c}(\boldsymbol{j})$ : element $j$ of the design factors. With $j$ from 1 to 36 ; $f_{\text {fac }}$ : function of design factors

$\boldsymbol{f}_{\text {fac }}=\sum_{j=1}^{n=36} \mathrm{fac}(j)$

$\operatorname{Sec}(j)$ : element $j$ of the WBAN security requirement. With $j$ from 1 to 36 ;

$f_{\text {Sec }}$ : function of security requirement

$\boldsymbol{f}_{\text {Sec }}=\sum_{j=1}^{n=36} \operatorname{Sec}(j)$

Perf(j) : element $j$ of the performance assessment indicators. With j from 1 to 36 ;

$f_{\text {Perf: }}$ function of the performance assessment indicators

$\boldsymbol{f}_{\text {Perf }}=\sum_{j=1}^{n=36} \operatorname{Perf}(j)$

Table 1 Characteristics identified for wban systems

36 Characteristics identified for WBAN Systems

\begin{tabular}{|c|c|c|c|c|c|}
\hline$N^{\circ}$ & Designations & $N^{\circ}$ & Designations & $N^{\circ}$ & Designations \\
\hline 1 & National Architecture & 13 & Robustness & 25 & Reliability \\
\hline 2 & Local architecture & 14 & Usability & 26 & The passage ladder (scaling) \\
\hline 3 & Dimension & 15 & Ergonomics & 27 & The flow \\
\hline 4 & Environment / Obstacle & 16 & Energetic efficiency & 28 & The Deadline \\
\hline 5 & Building material & 17 & interoperability & 29 & The Gigue/Jip \\
\hline 6 & Size to watch & 18 & Precision & 30 & Loss rate \\
\hline 7 & Mobility Management & 19 & Miniaturization & 31 & Life time \\
\hline 8 & Respect for private life & 20 & Reduced detection time & 32 & The availability \\
\hline 9 & Securing data & 21 & High security & 33 & Confidentiality \\
\hline 10 & Low cost of deployment & 22 & Tolerances to breakdowns & 34 & Integrity \\
\hline 11 & Easy installation & 23 & Sensitivity to Data Loss & 35 & Access control \\
\hline 12 & Flexibility & 24 & High sensitivity & 36 & Authentication \\
\hline
\end{tabular}


TABLE 2 The binary matrix of a functional WBAN network

\begin{tabular}{|c|c|c|c|c|c|c|c|c|c|c|c|}
\hline \multirow[t]{3}{*}{$\mathrm{N}^{\circ}$} & \multirow{3}{*}{$\begin{array}{l}\text { Referential characteristics of a } \\
\text { WBAN networkj with } j \\
\text { from } 1 \text { to } 36 .\end{array}$} & \multicolumn{10}{|c|}{ Requirements $\left(I_{i}\right)$ with $i$ from 1 to 5} \\
\hline & & \multicolumn{2}{|l|}{$\mathrm{I}_{1}$} & \multicolumn{2}{|l|}{$\mathrm{I}_{2}$} & \multicolumn{2}{|l|}{$\mathrm{I}_{3}$} & \multicolumn{2}{|l|}{$\mathrm{I}_{4}$} & \multicolumn{2}{|l|}{$\mathrm{I}_{5}$} \\
\hline & & \multicolumn{2}{|c|}{$\begin{array}{l}\text { Requirement } \\
\text { of medical } \\
\text { application } \\
\text { of WBAN }\end{array}$} & \multicolumn{2}{|c|}{$\begin{array}{l}\text { Key } \\
\text { Design } \\
\text { Factors } \\
\text { for } \\
\text { WBANs }\end{array}$} & \multicolumn{2}{|c|}{$\begin{array}{l}\text { WBAN } \\
\text { security } \\
\text { requirement }\end{array}$} & \multicolumn{2}{|c|}{$\begin{array}{l}\text { WBAN } \\
\text { Performance } \\
\text { Assessment } \\
\text { Indicators }\end{array}$} & \multicolumn{2}{|c|}{$\begin{array}{l}\text { Materio- } \\
\text { vigilance }\end{array}$} \\
\hline 1 & National Architecture & 1 & 0 & 1 & 0 & 1 & 0 & 1 & 0 & 1 & 0 \\
\hline 2 & Local architecture & 1 & 0 & 1 & 0 & 1 & 0 & 1 & 0 & 1 & 0 \\
\hline 3 & Dimension & 1 & 0 & 1 & 0 & 1 & 0 & 1 & 0 & 1 & 0 \\
\hline 4 & Environment / Obstacle & 1 & 0 & 1 & 0 & 1 & 0 & 1 & 0 & 1 & 0 \\
\hline 5 & Building material & 1 & 0 & 1 & 0 & 1 & 0 & 1 & 0 & 1 & 0 \\
\hline 6 & Size to watch & 1 & 0 & 1 & 0 & 1 & 0 & 1 & 0 & 1 & 0 \\
\hline 7 & Mobility Management & 1 & 0 & 1 & 0 & 1 & 0 & 1 & 0 & 1 & 0 \\
\hline 8 & Respect for private life & 1 & 0 & 1 & 0 & 1 & 0 & 1 & 0 & 1 & 0 \\
\hline 9 & Securing data & 1 & 0 & 1 & 0 & 1 & 0 & 1 & 0 & 1 & 0 \\
\hline 10 & Low cost of deployment & 1 & 0 & 1 & 0 & 1 & 0 & 1 & 0 & 1 & 0 \\
\hline 11 & Easy installation & 1 & 0 & 1 & 0 & 1 & 0 & 1 & 0 & 1 & 0 \\
\hline 12 & Flexibility & 1 & 0 & 1 & 0 & 1 & 0 & 1 & 0 & 1 & 0 \\
\hline 13 & Robustness & 1 & 0 & 1 & 0 & 1 & 0 & 1 & 0 & 1 & 0 \\
\hline 14 & Usability & 1 & 0 & 1 & 0 & 1 & 0 & 1 & 0 & 1 & 0 \\
\hline 15 & Ergonomics & 1 & 0 & 1 & 0 & 1 & 0 & 1 & 0 & 1 & 0 \\
\hline 16 & Energetic efficiency & 1 & 0 & 1 & 0 & 1 & 0 & 1 & 0 & 1 & 0 \\
\hline 17 & interoperability & 1 & 0 & 1 & 0 & 1 & 0 & 1 & 0 & 1 & 0 \\
\hline 18 & Precision & 1 & 0 & 1 & 0 & 1 & 0 & 1 & 0 & 1 & 0 \\
\hline 19 & Miniaturization & 1 & 0 & 1 & 0 & 1 & 0 & 1 & 0 & 1 & 0 \\
\hline 20 & Reduced detection time & 1 & 0 & 1 & 0 & 1 & 0 & 1 & 0 & 1 & 0 \\
\hline 21 & High security & 1 & 0 & 1 & 0 & 1 & 0 & 1 & 0 & 1 & 0 \\
\hline 22 & Tolerances to breakdowns & 1 & 0 & 1 & 0 & 1 & 0 & 1 & 0 & 1 & 0 \\
\hline 23 & Sensitivity to Data Loss & 1 & 0 & 1 & 0 & 1 & 0 & 1 & 0 & 1 & 0 \\
\hline 24 & High sensitivity & 1 & 0 & 1 & 0 & 1 & 0 & 1 & 0 & 1 & 0 \\
\hline 25 & Reliability & 1 & 0 & 1 & 0 & 1 & 0 & 1 & 0 & 1 & 0 \\
\hline 26 & The passage ladder (scaling) & 1 & 0 & 1 & 0 & 1 & 0 & 1 & 0 & 1 & 0 \\
\hline 27 & The flow & 1 & 0 & 1 & 0 & 1 & 0 & 1 & 0 & 1 & 0 \\
\hline 28 & The Deadline & 1 & 0 & 1 & 0 & 1 & 0 & 1 & 0 & 1 & 0 \\
\hline 29 & The Gigue/Jip & 1 & 0 & 1 & 0 & 1 & 0 & 1 & 0 & 1 & 0 \\
\hline 30 & Loss rate & 1 & 0 & 1 & 0 & 1 & 0 & 1 & 0 & 1 & 0 \\
\hline 31 & Life time & 1 & 0 & 1 & 0 & 1 & 0 & 1 & 0 & 1 & 0 \\
\hline 32 & The availability & 1 & 0 & 1 & 0 & 1 & 0 & 1 & 0 & 1 & 0 \\
\hline 33 & Confidentiality & 1 & 0 & 1 & 0 & 1 & 0 & 1 & 0 & 1 & 0 \\
\hline 34 & Integrity & 1 & 0 & 1 & 0 & 1 & 0 & 1 & 0 & 1 & 0 \\
\hline 35 & Access control & 1 & 0 & 1 & 0 & 1 & 0 & 1 & 0 & 1 & 0 \\
\hline 36 & Authentication & 1 & 0 & 1 & 0 & 1 & 0 & 1 & 0 & 1 & 0 \\
\hline
\end{tabular}

Matvig(j) : element $j$ of the materiovigilance. With $j$ from 1 to 36 ;

$f_{\text {Matvig: function of the materiovigilance }}$

$\boldsymbol{f}_{\text {Matvig }}=\sum_{j=1}^{n=36} \operatorname{Matvig}(j)$
Finally, the conception function $\boldsymbol{f}_{\boldsymbol{c}}(\boldsymbol{W B A} \boldsymbol{N})$ can be formulated like (6): 


$$
f_{c}(W B A N)=\left\{\begin{array}{l} 
\\
\boldsymbol{f}_{\boldsymbol{E}} \\
\boldsymbol{f}_{\text {fac }} \\
\boldsymbol{f}_{\text {Sec }} \\
\boldsymbol{f}_{\text {Perf }} \\
\boldsymbol{f}_{\text {Matvi }}
\end{array}\right.
$$

The design of a WBAN network for health care monitoring aims to optimize care in health systems by a smart network. Let us note:

$f_{\text {Snetw }}$ as function for the smart network healthcare monitoring.

$f_{e n}$ as function energy because one of the major operating constraints of WBAN networks is the energy. The smart network healthcare monitoring noted $\boldsymbol{f}_{\text {Snetw }}$ can be defined as in (7):

$\boldsymbol{f}_{\text {Snetw }}=\left\{\begin{array}{l}\max \left(f_{c}(W B A N)\right) \\ \min \left(\boldsymbol{f}_{\text {en }}\right)\end{array}\right.$
D. Assessment of physiological parameters monitorable by a network of sensors

Medical sensors are used to monitor 16 different groups of parameters (see Table 3) relating to physiological variables, physical activities, and movements of a person, social inclusion of the elderly or living with disabilities.

As regards the location, as Fig. 1 shows, the sensors can be placed at 17 different locations on a patient's body [6] [25] and can monitor 63 kinds of physical activity in a person's body.

As regards social inclusion, the network of medical sensors can monitor elderly people and living people with one of the six disabilities, namely: Cognitive disability, Disability in general, Intellectual disability, Parkinson's disease, Physical disability, and Visual impairment [2].

From the point of view of the available technologies and applications or services, 22 technologies and 75 applications/ services are available according to the literature [2] for the deployment of medical sensor networks.

TABLE 3 Physiological characteristics monitorable with sensor networks

$\mathrm{N}^{\circ}$ Physiological sources or characteristics

1 Combining bioelectrical (EEG) and bio-optical (NIRS) neurophysiological measurements

2 (Real-life environment) EEG: monitoring

3 Decoding of covert somatosensory attention (SAO)

4 Pulmonary function testing (PFT):

5 HCT of VAD patients

6 Identifying disease biomarkers (Precision Medicine)

7 Glucose Monitoring in Individuals With Diabetes

8 [Monitoring frail elderly patients with chronic disease(s) and patients with diabetes.]: blood pressure, weight, blood glucose, and $\mathrm{SpO}$,

9 Person's physical activity (PA) monitoring

1038 features extracted from HRV, SC, and EEG SIGNAL (SKIN conductance (SC): 16 / heart rate variability (HRV): 16 /SKIN CONDUCTANCE (SC: 16))

11 Photoplethysmographic (PPG) signals: $\mathrm{SpO} 2$

12 Cardiorespiratory system: Obstructive sleep apnea (OSA) detection ( $\mathrm{PaCO} 2),(\mathrm{SaO} 2),(\mathrm{ABP}),(\mathrm{HR}),(\mathrm{Vt}), \mathrm{SpO} 2$, virtual oxygen saturation state (VSO2))

13 Activities of Daily Living (ADL): energy balance, and quality of life (understanding)

14 Hemoglobin $(\mathrm{HbT})$, concentration and tissue oxygen saturation ( $\mathrm{StO} 2)$

15 Detection of Nocturnal Scratching Movements in Patients with Atopic Dermatitis

16 Detect the onset and duration of freezing of gait (FOG)
Sensor type, Methods, Technologies

A (M3BA) \& (NIRS) technology \& Brain-Computer Interfaces (BCI) [25]

Ear EEG Dry-Contact Electrode [26]. BCI and NeuroFeedback (NF)

somatosensory attentional orientation [27]

Depth (and) Microsoft Kinect V2 RGB-D sensors. [28]

Machine learning model to accurately predict the blood-analog viscosity during support of a pathological circulation with a rotary ventricular assist device (VAD). [29]

Biomedical Big Data analytics \& multi-omic data \& -Omic information into electronic health records (HER) [30]

Percutaneous glucose sensors with sending information by wirelessly [31]

Interoperable End-to-End Remote Patient Monitoring Platform Based on IEEE 11073 PHD and ZigBee Health Care Profile [5]

Smartwatch ZGPAX S8 [32]

A wearable physiological sensors system (Sensors-Type: IMU, EDA, $\mathrm{SpO} 2, \mathrm{ECG}, \mathrm{EDA}$, Microphone, Accelerometer, Proximity, Respiration, EMG, EEG) [3]

ESPRIT-MLT: [33]

Wearable sensor measurement signals(sensors: One-lead ECG, SpO2) with the mathematical models-Gaussian processes [21]

Insole Based, Wrist-Worn Wearable Sensors (SmartStep and Wrist Sensor) and ADL Sensors: Biaxial accelerometers, magnetometer, pressure sensors, heart rate sensor, visual sensors [6], Complex Network Analysis [34]

Wearable optical device [35]

Accelerometers and Recurrent Neural Networks [36]

Inertial Sensors (Accelerometers, Gyroscopes), electromyography (EMG) sensors, force resistive sensors, video-based gait analysis. [37] 


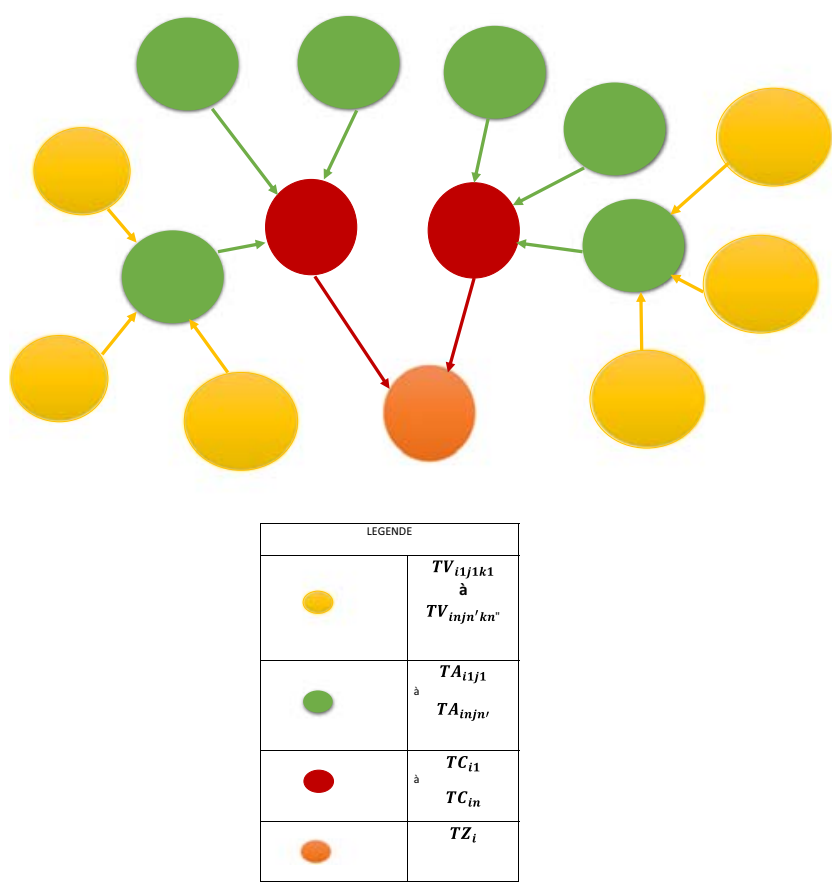

Fig. 3 Technocenters cloud of the Integrated Network for Patient Monitoring of a Health Zone (RIMP-ZS)

E. The modeling of the RIMP national architecture in the cloud Technocenters form

The health system of Benin is organized in 34 health zones. Each health zone is subdivided into village health unit (UVS), district health center (CSA), municipal health center (CSC) and zone hospital (HZ). We define a technocenter a health data monitoring center. Thus, for modeling the Benin Integrated Patient Monitoring Network (RIMP-B), the first step is to model each health zone, so that the data are decentralized by health care zone and then to interconnect such zones to have the RIMP. As a result, we see that the RIMP-B is a continuation of the RIMP by Health Zone (RIMP-ZS).

Let $i_{n}$ be the number of communes constituting a health care zone with $i_{1}, i_{2} \ldots . i_{n}$ the communes.

Let $j_{n^{\prime}}$ be the rounding number of each commune of a health zone with $j_{1}, j_{2} \ldots . . j_{n^{\prime}}$.

Let $k_{n^{\prime \prime}}$ be the number of villages in each district.

Let $T C_{i_{n}}$ the municipal technocentres representing the CSCs of a health zone and $T A_{i_{n_{n_{n}}}}$ technocenters of districts representing the CSA of the districts of each commune with $i_{1 \ldots \ldots} i_{n ;}, j_{1} \ldots . j_{n^{\prime}}$.

For example:

For $T C_{i_{1}}$ the technocenters of the first commune of a sanitary zone, we have $T A_{i_{1} j_{1}} \ldots \ldots . . T A_{i_{1} j_{n^{\prime}}}$ technocenters of the boroughs of this commune.

Let $T V_{i_{n} j_{n} k_{n} k^{\prime}}$ be the village technocentres representing the UVS of each district with $i_{n}$ going from de $i_{1}$ to $i_{n} ; j_{n^{\prime}}$ going from $j_{1}$ to $j_{n^{\prime}}$ and $k_{n^{\prime \prime}}$ going from de $k_{1}$ to $k_{n^{\prime \prime}}$.
For example: for $i_{1}$ and $j_{1}$ we have $T V_{i_{1} j_{1} k_{1}}$ to $T V_{i_{1} j_{1} k_{n\}} \text {. }}$.

Let $T Z_{l}$ be the technocentres representing the monitoring centers of the health zones with $l$ ranging from 1 to 34 , because the Beninese health system has 34 sanitary zones. The Technocenters cloud of the Integrated Patient Monitoring Network of a health zone (RIMP-ZS) is shown in Fig.3.

Let $T D_{m}$ the departmental technocenter regrouping the technocenters of the zones $\left(T Z_{l}\right)$, representing the departmental health departments (DDS). We then have the technocentres cloud of the Departmental Integral Patient Monitoring Network (RIMP-DDS), shown in Fig. 4.

F. The simulation of the functionality of each Technocentre: software architecture.

The software architecture of the smart hospital, shown in Fig. 6, shows the various management software modules. This architecture also illustrates the exchanges between the different servers. The data server (Fig. 6) is responsible for collecting the data (i.e., physiological and actimetric parameters) and storing them in a technocenter database via the acquisition module and / or the network. This same module sends this data to the display module in order to follow the patients in real time and to display the alerts in case of detection of critical cases. The omics data are sent to the calculation server via the send/receive module and stored in a second database (zone, departmental, national). The delayed calculation module retrieves these data in order to generate the thresholds of the behavioral deviation, nocturnal agitation, prolonged immobility, residence time in the bathroom, the difference between physiological parameters and others. These thresholds of the different physiological parameters are therefore sent directly to the database of the local technocentre. This is to allow the diagnostics module to compare them with the current data and generate alerts (on the real-time application and phones) in case of overruns.

G. Estimation of the material resources of the national RIMP according to physiological parameters

An analysis of the different parameters, which can be monitored with the population size of each village (or city district), shows that the size of the RIMP resources would be unique for each health zone. Moreover, the size of the RIMP would also depend on the different services offered by each branch of the sanitary system. (UVS, CSA, CSC, HZ). An estimate of the RIMP material resources would then be a function of the different elements involved. Let us designate by $f_{\text {mat }}$ the material resources function. This function $f_{\text {mat }}$ is size-dependent $T$ data to monitor which itself depends on the size $N$ population and number of sensors $N_{c}$ placed on the patient. This hardware function also depends on the number of 
Fig. 4 Technocenters Cloud of the Integrated Patient Monitoring Network of a Department (RIMPDDS)

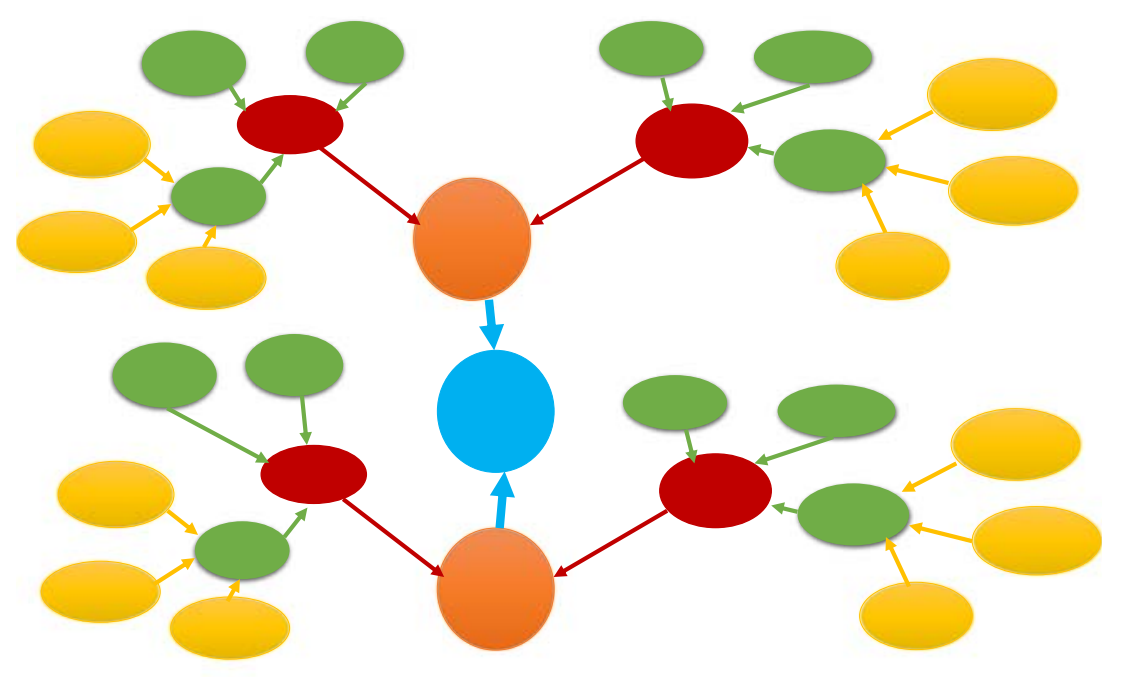

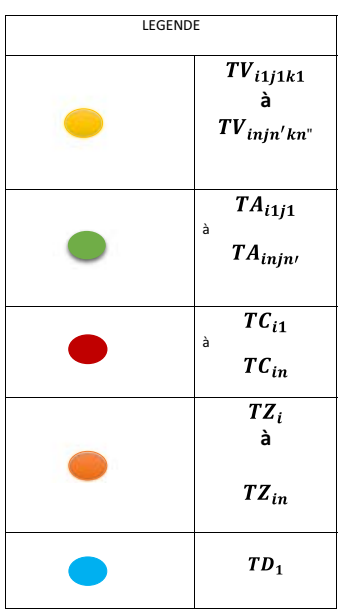

simultaneous data access $(N p+N c m+N a d m)$, with $N p$ the number of patients, $\mathrm{Ncm}$ the number of the medical profession and Nadm the number of administrative technocenters. Function $f_{\text {mat }}$ would be equal to Eq. (8):

$f_{\text {mat }}=f(T, N p, N c m, N a d m)$

\section{Analysis and discussion}

In light of the challenges of the Beninese health system, our solution aims to make it efficient from the villages to the cities. The solution will also comprise of a powerful health system allowing the prediction of health statuses based on the acquired data. The implementation of this solution will go through several stages (from the analysis of ICT potential in the 5295 villages and city districts to the technological choice). Several design factors for WBAN networks (i.e., scalability, quality of service (QoS), power consumption, wireless technology) should be considered [8] [26]. Many works in the literature deal with the application of WBAN networks for health [15] [38] This work presents, on the one hand, the characteristics and the requirements of the medical application of WBAN networks, and on the other hand the characteristics and design factors of these networks. The design of WBAN networks also involves security requirements (WBAN and traditional networks have the same security requirements) [19] [23] However, these works are different from ours since we propose a repository of 36 elements according to five requirements that the design must follow for the patient monitoring network. Besides, each requirement is a matrix block that serves as a compass for the design and/or evaluation of a patient monitoring system.

As regards security threats or attacks, such as modifying and listening to medical data, activity detection and location, and hacking security systems and alarms, they can occur and their eventuality should be taken into account [19] [23] Our repository, in fact, considers this.

Moreover, network data flows and capacity are among the parameters that impact network performance. In this scenario, the choice of high-speed wireless technology provides 


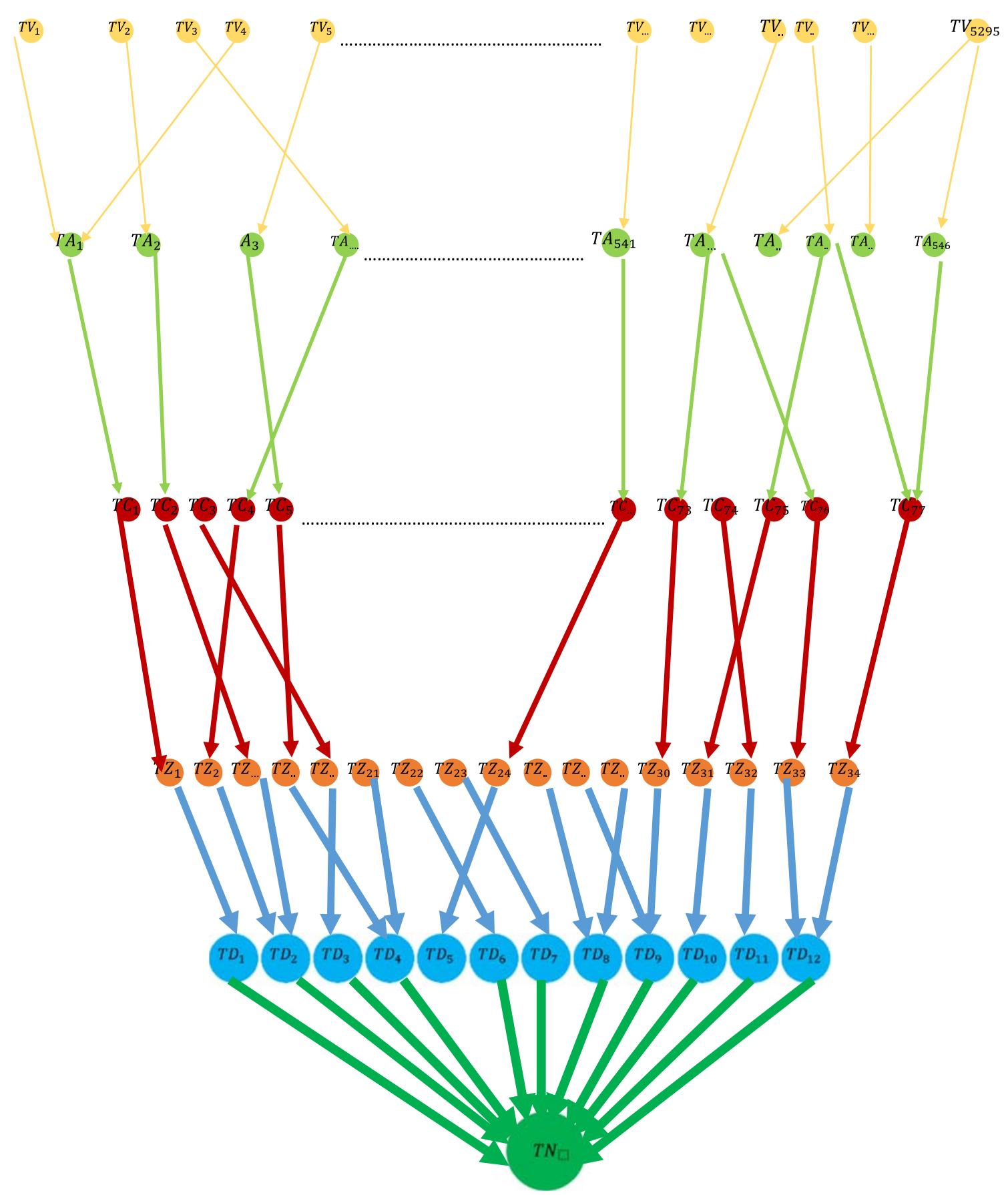

Fig. 5 Technocenters cloud of the Benin Integrated Patient Monitoring Network

benefits to meet network scalability and increased the number of people being monitored. On the other hand, other technologies allow low energy consumption, but significant delays (generation) and/or low transfer rates. The chosen technology, thus, will be a compromise between flow and energy consumption.

As several technologies are used in patient monitoring architectures to provide multiple services [21] [39], we have started identifying all the technologies used with the different services. Based on this, our work expands this knowledge as it proposes the essential features of any surveillance system tailored to the Beninese health system along with the different possible positions, where the sensors could be placed on a patient's body. This is the strength of this work.

Compared to several works in literatures, in which technological choices are proposed [40] [41] [28], our work presents a basic model for setting up a patient monitoring network, specifically contextualized to the situation of the Beninese healthcare system. 


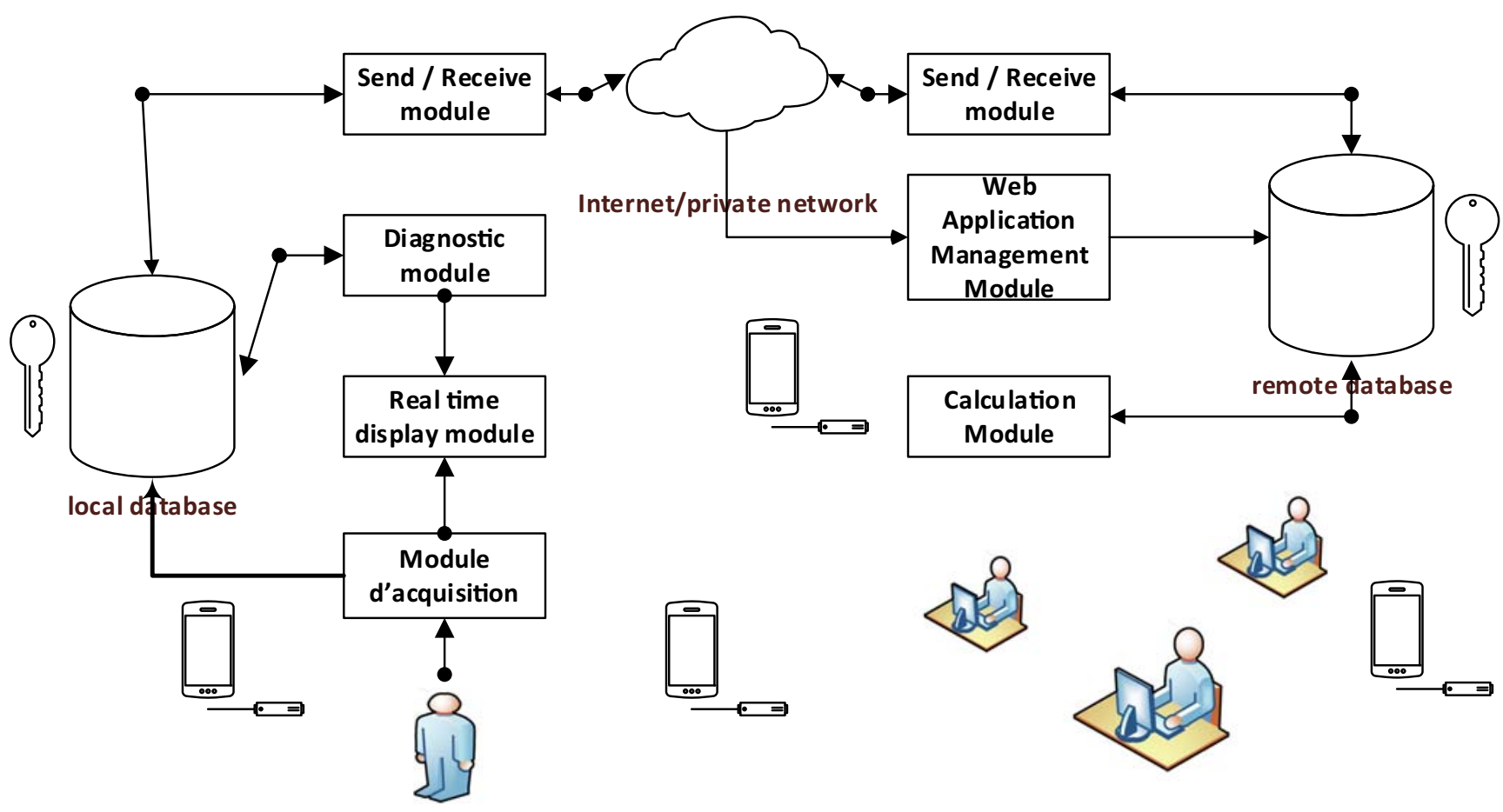

Sensor Network

Fig. 6 Software architecture of the smart hospital

\section{Conclusion}

MWSN/WSN are a revolution in wireless computer networks. The choice of a technology will depend strongly on the available solutions and the vision of the proposer. However, features such as power, data flow and parameters related to scope, cost, security, and number of nodes should be considered.

In the case of Benin, the need for a health system, which responds to the many reported challenges and gives importance to the population independently from the area or region of inhabitance, is compelling. This inspired our work, which proposed a reference system for the implementation of a patient monitoring system, which modeled a network for the Benin health system. This work also presented how the sensors could be placed and the different physiological parameters that could be monitored according to the services offered.

The implementation of this proposed RIMP-B will go through several stages and future work will consist of a field survey across the country to:

1) Validate the data of the sanitary cartography;

2) Identify ICT potentials and different constraints of each localized health mapping;

3) Propose the different technologies to be used in each health locality for the proper functioning of technocenters;

4) Propose an algorithm for the calculation of the material resources applicable to each level.
In this work, we have not yet proposed the architecture of each technocentre, because it is linked to future work. Furthermore, once the architecture has been defined, we will implement it in a hospital center.

Funding information There is no funding source

\section{Compliance with ethical standards}

Conflict of interest The authors declare that they have no conflict of interest.

Ethical approval This article does not contain any studies with human participants or animals performed by any of the authors.

Informed consent Informed consent was obtained from all individual participants included in the study.

Open Access This article is licensed under a Creative Commons Attribution 4.0 International License, which permits use, sharing, adaptation, distribution and reproduction in any medium or format, as long as you give appropriate credit to the original author(s) and the source, provide a link to the Creative Commons licence, and indicate if changes were made. The images or other third party material in this article are included in the article's Creative Commons licence, unless indicated otherwise in a credit line to the material. If material is not included in the article's Creative Commons licence and your intended use is not permitted by statutory regulation or exceeds the permitted use, you will need to obtain permission directly from the copyright holder. To view a copy of this licence, visit http://creativecommons.org/licenses/by/4.0/. 


\section{References}

1. M. D. L. S. Bénin, Plan national de dévéloppement sanitaire, Ministère de la Santé Bénin, Cotonou,Bénin, 2009.

2. M. Manzoor et V. Vimarlund, « Digital technologies for social inclusion of individuals with disabilities ", Health Technol., vol. 8, n ${ }^{\circ}$ 5, p. 377-390, nov. 2018, doi: https://doi.org/10.1007/ s12553-018-0239-1.

3. S. Betti et al., « Evaluation of an Integrated System of Wearable Physiological Sensors for Stress Monitoring in Working Environments by Using Biological Markers », IEEE Transactions on Biomedical Engineering, vol. 65, n ${ }^{\circ}$ 8, p. 1748-1758, août 2018, doi: https://doi.org/10.1109/TBME.2017.2764507.

4. A. Makke, « Détection d'attaques dans un système WBAN de surveillance médicale à distance », thesis, Paris 5, 2014.

5. Clarke M, de Folter J, Verma V, Gokalp H. Interoperable end-to-end remote patient monitoring platform based on IEEE 11073 PHD and ZigBee health care profile. IEEE Trans Biomed Eng. 2017:1-1. https://doi.org/10.1109/TBME.2017.2732501.

6. N. Hegde, M. Bries, T. Swibas, E. Melanson, et E. Sazonov, « Automatic Recognition of Activities of Daily Living Utilizing Insole-Based and Wrist-Worn Wearable Sensors », IEEE Journal of Biomedical and Health Informatics, vol. 22, n ${ }^{\circ} 4$, p. 979-988, juill. 2018, doi: https://doi.org/10.1109/JBHI.2017.2734803.

7. S. Gutta, Q. Cheng, H. D. Nguyen, et B. A. Benjamin, « Cardiorespiratory Model-Based Data-Driven Approach for Sleep Apnea Detection ", IEEE Journal of Biomedical and Health Informatics, vol. 22, $\mathrm{n}^{\mathrm{o}} 4$, p. 1036-1045, juill. 2018, doi: https:// doi.org/10.1109/JBHI.2017.2740120.

8. S. Charlton et al., « Architecture for field upgrade of a health monitoring system », US8978026B2, 10-mars-2015.

9. «Wireless Sensor Network and Web Application Hybrid Scheme for Healthcare Monitoring | Ali | Journal of Soft Computing and Decision Support Systems ». .

10. Hung K, Lee CC, Choy SO. Ubiquitous health monitoring: integration of wearable sensors, novel sensing techniques, and body sensor networks. In: Adibi S, editor. Mobile health, vol. 5. Cham: Springer International Publishing; 2015. p. 319-42.

11. P. Kakria, N. K. Tripathi, et P. Kitipawang, « A Real-Time Health Monitoring System for Remote Cardiac Patients Using Smartphone and Wearable Sensors ", International Journal of Telemedicine and Applications, 2015. [En ligne]. Disponible sur: https://www. hindawi.com/journals/ijta/2015/373474/. [Consulté le: 30-janv2020].

12. N. Dey, A. S. Ashour, F. Shi, S. J. Fong, et R. S. Sherratt, « Developing residential wireless sensor networks for ECG healthcare monitoring ", IEEE Transactions on Consumer Electronics, vol. 63, n 4, p. 442-449, nov. 2017, doi: https://doi. org/10.1109/TCE.2017.015063.

13. Puvaneshwari S Vijayashaarathi S, « Efficient Monitoring system for cardiac patients using Wireless Sensor Networks (WSN) 》, in 2016 International Conference on Wireless Communications, Signal Processing and Networking (WiSPNET), Chennai, India, 2016, p. 1558-1561, doi: https://doi.org/10.1109/WiSPNET.2016. 7566398

14. B. Xu, L. Xu, H. Cai, L. Jiang, Y. Luo, et Y. Gu, « The design of an $\mathrm{m}$-Health monitoring system based on a cloud computing platform ", Enterprise Information Systems, vol. 11, $\mathrm{n}^{\mathrm{o}}$ 1, p. 17-36, janv. 2017, doi: https://doi.org/10.1080/17517575.2015.1053416.

15. U. Gogate J. W. Bakal, « Smart Healthcare Monitoring System based on Wireless Sensor Networks », in 2016 International Conference on Computing, Analytics and Security Trends (CAST), Pune, India, 2016, p. 594-599, doi: https://doi.org/10.1109/CAST. 2016.7915037.
16. K. Dragos et K. Smarsly, «A comparative review of wireless sensor nodes for structural health monitoring », p. 10.

17. G. Tuna, «Wireless Sensor Network-Based Health Monitoring System for the Elderly and Disabled », International Journal of Computer Networks and Applications, vol. 2, $\mathrm{n}^{\circ}$ 6, p. 7, 2015.

18. N. M. B. Veerappa, « MONITORING OF PATIENT HEALTH USING IOT SENSORS ».

19. D. Sathya et P. Ganesh Kumar, « Secured remote health monitoring system », Healthcare Technology Letters, vol. 4, n ${ }^{\circ}$ 6, p. 228-232, déc. 2017, doi: https://doi.org/10.1049/htl.2017.0033.

20. C. C. Y. Poon, Yuan-Ting Zhang, et Shu-Di Bao, « A novel biometrics method to secure wireless body area sensor networks for telemedicine and m-health », IEEE Commun. Mag., vol. 44, $\mathrm{n}^{\mathrm{o}}$ 4, p. 73-81, avr. 2006, doi: https://doi.org/10.1109/MCOM.2006. 1632652.

21. W. Bourennane, «Étude et conception d'un système de télésurveillance et de détection de situations critiques par suivi actimétrique des personnes à risques en milieu indoor et outdoor », phdthesis, Université Toulouse le Mirail - Toulouse II, 2013.

22. F. A. Allaert et N. J. Mazen, «Évaluation des objets connectés et des applications de santé », Actualités Pharmaceutiques, vol. 55, ${ }^{\circ}$ 556, p. 29-32, mai 2016, doi: https://doi.org/10.1016/j.actpha. 2016.03.006.

23. H. Mshali, T. Lemlouma, M. Moloney, et D. Magoni, « A survey on health monitoring systems for health smart homes ", International Journal of Industrial Ergonomics, vol. 66, p. 26-56, juill. 2018, doi: https://doi.org/10.1016/j.ergon.2018.02.002.

24. H. Alemdar et C. Ersoy, « Wireless sensor networks for healthcare: A survey », Computer Networks, vol. 54, n ${ }^{\circ} 15$, p. 2688-2710, oct. 2010, doi: https://doi.org/10.1016/j.comnet.2010.05.003.

25. N. Jalloul, F. Porée, G. Viardot, P. L'Hostis, et G. Carrault, « Activity Recognition Using Complex Network Analysis », IEEE Journal of Biomedical and Health Informatics, vol. 22, $\mathrm{n}^{\mathrm{o}} 4$, $\mathrm{p}$. 989-1000, juill. 2018, doi: https://doi.org/10.1109/JBHI.2017. 2762404.

26. I. F. Akyildiz, T. Melodia, et K. R. Chowdhury, « A survey on wireless multimedia sensor networks », Computer Networks, vol. 51, no 4, p. 921-960, mars 2007, doi: https://doi.org/10.1016/j. comnet.2006.10.002.

27. I. F. Akyildiz, T. Melodia, et K. R. Chowdhury, « Wireless Multimedia Sensor Networks: Applications and Testbeds », Proceedings of the IEEE, vol. $96, \mathrm{n}^{\circ} 10$, p. 1588-1605, oct. 2008, doi: https://doi.org/10.1109/JPROC.2008.928756.

28. C. S. Bingham et al., « Model-Based Analysis of Electrode Placement and Pulse Amplitude for Hippocampal Stimulation », IEEE Transactions on Biomedical Engineering, vol. 65, $\mathrm{n}^{\mathrm{o}} 10, \mathrm{p}$. 2278-2289, oct. 2018, doi: https://doi.org/10.1109/TBME.2018. 2791860.

29. A. von Luhmann, H. Wabnitz, T. Sander, et K. R. Muller, « M3BA: A Mobile, Modular, Multimodal Biosignal Acquisition Architecture for Miniaturized EEG-NIRS-Based Hybrid BCI and Monitoring », IEEE Trans. Biomed. Eng., vol. 64, nº 6, p. 1199 1210, juin 2017, doi: https://doi.org/10.1109/TBME.2016. 2594127.

30. S. L. Kappel, M. L. Rank, H. O. Toft, M. Andersen, et P. Kidmose, « Dry-Contact Electrode Ear-EEG », IEEE Trans. Biomed. Eng., vol. $66, \mathrm{n}^{\circ} 1$, p. $150-158$, janv. 2019, doi: https://doi.org/10.1109/ TBME.2018.2835778.

31. C. Jeunet, F. Lotte, J. M. Batail, P. Philip, et J. A. Micoulaud Franchi, «Using Recent BCI Literature to Deepen our Understanding of Clinical Neurofeedback: A Short Review », Neuroscience, vol. 378, p. 225-233, mai 2018, doi: https://doi. org/10.1016/j.neuroscience.2018.03.013.

32. L. Yao, X. Sheng, N. Mrachacz-Kersting, X. Zhu, D. Farina, et N. Jiang, « Decoding Covert Somatosensory Attention by a BCI System Calibrated With Tactile Sensation », IEEE Transactions 
on Biomedical Engineering, vol. 65, nº 8, p. 1689-1695, août 2018, doi: https://doi.org/10.1109/TBME.2017.2762461.

33. V. Soleimani et al., « Remote, Depth-Based Lung Function Assessment », IEEE Transactions on Biomedical Engineering, vol. $64, \mathrm{n}^{\circ} 8$, p. 1943-1958, août 2017, doi: https://doi.org/10. 1109/TBME.2016.2618918.

34. A. Petrou, M. Kanakis, S. Boës, P. Pergantis, M. Meboldt, et M. S. Daners, « Viscosity Prediction in a Physiologically Controlled Ventricular Assist Device », IEEE Transactions on Biomedical Engineering, vol. 65, n ${ }^{\circ} 10$, p. 2355-2364, oct. 2018, doi: https:// doi.org/10.1109/TBME.2018.2797424.

35. P. Y. Wu, C. W. Cheng, C. D. Kaddi, J. Venugopalan, R. Hoffman, et M. D. Wang, «-Omic and Electronic Health Record Big Data Analytics for Precision Medicine ", IEEE Transactions on Biomedical Engineering, vol. 64, $\mathrm{n}^{\mathrm{o}}$ 2, p. 263-273, févr. 2017, doi: https://doi.org/10.1109/TBME.2016.2573285.

36. J. Y. Lucisano, T. L. Routh, J. T. Lin, et D. A. Gough, « Glucose Monitoring in Individuals With Diabetes Using a Long-Term Implanted Sensor/Telemetry System and Model », IEEE Transactions on Biomedical Engineering, vol. 64, n ${ }^{\circ}$ 9, p. 1982 1993, sept. 2017, doi: https://doi.org/10.1109/TBME.2016. 2619333.

37. J. D. Amor et C. J. James, « Validation of a Commercial Android Smartwatch as an Activity Monitoring Platform », IEEE Journal of
Biomedical and Health Informatics, vol. 22, $\mathrm{n}^{\circ}$ 4, p. 968-978, juill. 2018, doi: https://doi.org/10.1109/JBHI.2017.2732678.

38. A. Goyal et al., « Smart Home Health Monitoring System for Predicting Type 2 Diabetes and Hypertension », Journal of King Saud University - Computer and Information Sciences, janv. 2020, doi: https://doi.org/10.1016/j.jksuci.2020.01.010.

39. «A wireless sensor network monitoring system for highway bridges - IEEE Conference Publication ». [En ligne]. Disponible sur: https:// ieeexplore.ieee.org/abstract/document/7162953. [Consulté le: 31janv-2020].

40. S. A. Butt, J. L. Diaz-Martinez, T. Jamal, A. Ali, E. De-La-HozFranco M. Shoaib, « IoT Smart Health Security Threats », in 2019 19th international conference on computational science and its applications (ICCSA), Saint Petersburg, Russia, 2019, p. 26-31, doi: https://doi.org/10.1109/ICCSA.2019.000-8.

41. A. R. Krishnan, S. Jayanth, et R. Janani, " Patient Pulse Rate Monitoring System Using LabVIEW | SpringerLink ». [En ligne]. Disponible sur: https://link.springer.com/chapter/10.1007/978-98115-1071-7_45. [Consulté le: 31-janv-2020].

Publisher's note Springer Nature remains neutral with regard to jurisdictional claims in published maps and institutional affiliations. 